\title{
ALGUNAS CONSIDERACIONES SOBRE LA EXPERIENCIA ESTÉTICA: ¿IDEOLOGÍA ESTÉTICA O POSIBILIDAD CRÍTICA?
}

\author{
NaÍm GaRNica* \\ doi:10.11144/Javeriana.uph35-70.acee
}

\section{RESUMEN}

El artículo intenta reconstruir de qué modo la experiencia estética se habría convertido en una categoría central de la estética contemporánea. A partir del aporte de distintos teóricos y filósofos del arte, pretendemos acercarnos a las potencialidades y límites de esta categoría, prestando atención tanto a los planteos que la defienden, como también a aquellos que la acusan de constituirse en una nueva forma ideológica. Al parecer, el concepto de obra de arte se ha vuelto obsoleto y la comprensión de los procesos del arte actual se ha canalizado mediante el concepto de experiencia estética.

Palabras clave: experiencia estética; política; filosofía; obra de arte

\footnotetext{
Universidad Nacional de Catamarca, San Fernando del Valle de Catamarca, Argentina - CONICET, Buenos Aires, Argentina.

Correo electrónico: naim_garnica@hotmail.com

Para citar este artículo: GARNICA, N. (2018). Algunas consideraciones sobre la experiencia estética: ¿Ideología o posibilidad crítica? Universitas Philosophica, 35(70), pp. 229-250. ISSN 01205323, ISSN en línea 2346-2426 doi:10.11144/Javeriana.uph35-70.acee

Parte de este trabajo ha sido presentado en el XVII Congreso de Filosofía de AFRA, llevado a cabo en la Universidad Nacional del Litoral en la Facultad de Humanidades y Ciencias, en los días 4 al 8 de agosto de 2015.
} 


\title{
SOME CONSIDERATIONS ON AESTHETIC EXPERIENCE: AESTHETIC IDEOLOGY OR CRITICAL POSSIBILITIES?
}

\author{
NaÍm GarNica
}

\begin{abstract}
This paper attempts to reconstruct how the category of aesthetic experience has become central in contemporary aesthetics. Drawing from the contribution of different theorists and philosophers of art we approach the potential and limits of this category, paying attention to both proposals that defend it, and to criticisms that accuse it of having become a new form of ideology. Apparently, the concept of work of art has become obsolete, and the understanding of contemporary art has been channeled through the concept of aesthetic experience.
\end{abstract}

Keywords: aesthetic experience; politics; philosophy; work of art 


\section{Introducción}

LAS CONSIDERACIONES EN TORNO A LA CRISIS del concepto de obra de arte en la estética filosófica han sido una constante desde las vanguardias artísticas en adelante. El vacío dejado por ese concepto, central en la tradición estética, pareciera ser llenado progresivamente por el de experiencia estética. Justamente, intentaremos presentar algunas consideraciones alrededor de esta categoría, así como las incidencias que esta tiene en la pretensión de verdad de la apariencia estética. El análisis mostrará diversas formas de conceptualizar este tipo de experiencia, sus posibles limitaciones y excesos. Para lo primero nos serviremos de los escritos del filósofo alemán Christoph Menke $(1997,2011)$ y para las críticas a la experiencia estética apelaremos al ensayo The Ideology of the Aesthetic Experience. An Attempt at Repoliticizing, de Ruth Sonderegger (2010). Antes de ingresar al debate entre estos autores, sin embargo, parece necesario realizar un breve recorrido por la historia del concepto de experiencia estética.

Durante mucho tiempo la experiencia estética (en adelante EE) se ha vuelto uno de los conceptos más determinantes de las discusiones dentro de la tradición estética. Aunque durante mucho tiempo tuvo este estatus, pues incluso permitió ampliar su conceptualización a aquellas experiencias no-artísticas, la EE se encontró contemporáneamente bajo una creciente crítica. Autores como JeanMarie Schaeffer (2013) proponen un concepto de experiencia estética que se reduce a procesos cognitivos, naturales o biológicos y gran parte de la tradición analítica de la estética lleva a cabo esta operación; en esta línea pueden encontrarse las discusiones de la primera parte del volumen Aesthetic Experience, editado por Richard Shusterman y Adele Tomlin (2008), y los diagnósticos sobre la destrucción de la experiencia estética y sus críticas en Jay (2001).

Para otros autores, sin embargo, la EE es única y diferente de los demás tipos de experiencia. Por caso, Martin Jay en Cantos de experiencia (2009) sostiene que mediante este concepto se logró valorizar el cuerpo en la tradición que va de Kant a Dewey y en los desarrollos posteriores, aunque su estudio en este texto es más extenso (va de Bacon al posestructuralismo). En esta dirección, la EE habría encontrado en los desarrollos de la filosofía continental otro modo de ser comprendida. A juicio de Juliane Rebentisch (2011), existirían al menos dos categorías necesarias para acercarse al arte contemporáneo y a la tradición estética. 
Ellas son, por una parte, el cruce de fronteras, que permitió cuestionar la idea de un arte integrado, unificado y modélico; y, por otra, la experiencia estética. Esta última habría estado motivada por los cambios y desarrollos artísticos, pero su característica fundamental sería que "ya no intenta conceptualizar el contenido de verdad de las obras de arte en el marco de un sistema filosófico" (Rebentisch 2011, p. 60). Rebentisch se refiere, específicamente, a la tradición de la estética filosófica alemana, en particular a los trabajos y debates de autores como Andrea Kern (2000, Christoph Menke (1997), Martin Seel (2010), Ruth Sonderegger (2000), Albrecht Wellmer (1991) y Christel Fricke (2001), entre otros. La mayoría de estos trabajos permitirían poner en cuestión la supuesta unidad de la obra de arte como forma explicativa del arte. Esto, a su vez, beneficiaría la pérdida de fundamento de la idea de progreso que se encuentra tras la idea modernista del arte. Sin embargo, Rebenstisch no cree que esto sea el fin del arte o de su historia. Lo que ella advierte es el cambio de enfoque sobre dichas problemáticas. La idea de objetivismo en el arte no cumpliría ya, frente al arte contemporáneo, con una explicación adecuada a sus exigencias. Pese a ello, esto no supondría que la crítica estuviera dirigida "contra lo estético y su autonomía en cuanto tal [...], sino como un movimiento que viene al menos en parte motivado por una comprensión distinta de lo estético y de su autonomía" (Rebenstisch, 2011, p. 62).

En consecuencia, la EE no sería ya una respuesta pasiva con respecto al arte; antes bien, supondría la capacidad para desarrollar la verdadera autonomía personal y la crítica del contexto social y político de nuestras vidas. En este marco, tal categoría se entiende como un modo de conocimiento que, al no ser ya ni discursivo, ni conceptual, permitiría tener experiencias distintivas que reconfiguran la conciencia. Para el pensamiento poskantiano, la EE permitiría cultivar una forma de libertad que no está marcada por el predominio del pensamiento sobre el sentido. Martin Jay (2009) describe este proceso como un cambio del modelo de la mera autonomía al modelo de la soberanía del arte:

Si cualquier historia del discurso ulterior de la experiencia estética es particularmente compleja, ello se debe a la dificultad que tuvo dicha experiencia en mantener sus límites como una subesfera completamente autónoma de la totalidad social/cultural. Pues no solo podía extenderse más allá de la recepción y la contemplación, de modo de incluir la creación, sino también operar como un modelo para la experiencia vivida en su conjunto. Es decir, según sus 
defensores, la cuestión no residía en cultivar la capacidad de apreciar y juzgar obras de arte o incluso ver el mundo a través de la lente de una sensibilidad estética sino, más bien, en vivir la vida como si esta fuera una obra de arte [...]. [E]l objeto de esa búsqueda podía reducirse, tácitamente, a un medio para producir un efecto en el sujeto (o dicho con más precisión, para lograr una unidad indisoluble entre sujeto y objeto) (p. 174).

Este último modelo pretendería devolverle al mundo su encanto haciendo uso de la EE. Su esperanza radicaría “[...] en que el arte fuera el vehículo para superar las racionalidades plurales de una modernidad fragmentada y, por tanto, trascender los límites de la razón misma [...]. Era posible celebrar la experiencia estética como totalizadora de las diversas capacidades humanas" (Jay, 2009, p. 176).

En el análisis que propone Jay de la tradición estética continental desde Kant y su recepción en el idealismo y el romanticismo, la EE comenzaría a adquirir una capacidad activa en la producción del sujeto y, paulatinamente, abandonaría su sentido contemplativo, receptivo y pasivo. De ese modo, la EE podría trasladarse a un "modelo productivista derivado de la idea griega de poiesis, en el cual el arte implicaba una creación espontánea que no se ceñía servilmente a las reglas de la tradición" (Jay, 2009, pp. 176-177). En ese caso, la EE no solo expandiría su sentido limitado, esto es, circunscripto exclusivamente al arte, además podría dar respuestas frente al mundo, incluso transformarlo y "quizá hasta redimirlo" (Jay, 2009, p. 177). Sin embargo, el modelo soberano de dicha experiencia puede acarrear problemas. Si bien su expansión permitiría, por medio de la apreciación estética, establecer un vínculo con culturas hasta entonces denigradas, la extensión de esa relación a todos los lazos del mundo corre el peligro de caer en la advertencia benjaminiana sobre la estetización de la política.

De algún modo, la EE en la filosofía poskantiana se encontraría en una tensión entre experimentar aquello que sucede o acaece frente al sujeto, donde el vínculo con el mundo no es un costado del sujeto, o bien un modelo de experiencia que buscaría convertir todas las experiencias en experiencias estéticas. En palabras de Jay (2009): “[1]a construcción de una identidad fáustica, narcisista, y la agresiva autoafirmación eran, pues, inferiores a la postura más humilde de aguardar a que las experiencias acontecieran, en vez de anhelar impacientemente la novedad y la variedad por sí mismas” (p. 179). Precisamente, sería esta tensión, 
creemos, la que se reproduce en el debate entre Ruth Sonderegger (2010) y los teóricos de la EE como Christoph Menke (1997) y Martin Seel (2010). Si bien las críticas a los teóricos de la EE ya las había realizado Rüdiger Bubner (2010) en su texto programático "Sobre algunas condiciones de la estética actual", publicado originalmente en alemán en 1973, y republicado en 1989, Sonderegger (2010) radicaliza algunas de esas críticas y las pone en relación con la ideología y la apariencia estética. En este caso, solo reconstruiremos el debate entre Menke y Sonderegger, dado que el primero es quien más defendería y desarrollaría un modelo de soberanía del arte a partir del concepto de EE como forma de crítica y, además, a quien parecieran estar dirigidas las críticas de la segunda.

\section{La experiencia estética según Menke}

Los textos del filósofo Christoph Menke $(1997,2011)$ intentan, de algún modo, responder a la cuestión de la naturaleza de la $\mathrm{EE}^{1}$. El autor parte de la dificultad de reducir la EE a categorías objetivas dualistas o entidades ontológicas. Su propuesta consistiría en explicar el modelo de la soberanía del arte por medio de una dialéctica de la estética, en la cual, filosofía y poesía se ven enfrentadas. Menke sostiene que la pérdida de significado de la estética filosófica en relación con otros campos filosóficos tiene su origen en el hecho de que los filósofos académicos tratan de asegurar un lugar de la estética filosófica como productora de conocimiento. Sin embargo, a juicio de Menke, la estética filosófica no produciría conocimiento; por el contrario, ella sería un reflejo crítico del propio proceso filosófico. En su ensayo "La dialéctica de la estética" Menke (2011) afirma:

1 Nuestra exposición se nutre de la interpretación de la obra de Menke planteada por Michel Ratté (1997) en "Christoph Menke: herméneutique, déconstruction et raison dans le problème de l'expérience esthétique". Cabe aclarar que el texto de Ratté limita su alcance a $L a$ soberania del arte de Menke, contextualizando su discusión en el marco de la teoría crítica y los cuestionamientos de Habermas a las fuentes deconstructivistas de ese trabajo, así como de los debates con la hermenéutica de Gadamer. En nuestro caso, extendemos esas consideraciones, intentando situarlo en el debate contemporáneo sobre las formas de explicación y acercamiento al arte de la estética filosófica. 
La estética, al desarrollar la controversia entre lo estético y la filosofía, tiene que convertirse en consecuencia también en una crítica de la crítica. Ésta es una crítica que ya no es crítica: la crítica de la crítica que la estética formula con respecto a la praxis estética es una metacrítica, una crítica de la crítica que incluye una libertad de la crítica, por muy momentánea que sea (p. 161).

La inclusión de la estética en la filosofía no podría ser entendida como una incorporación pasiva de un elemento que se convierte en objeto de la reflexión filosófica. La EE en el plano de la filosofía supondría "llevar la controversia con lo estético a la filosofía” (Menke, 2011, p. 159). Según Menke, la EE podría entenderse como un modo de autorreflexión de la práctica común, pero también podría constituirse como una autorreflexividad de la filosofía. En ese sentido, entiende a la estética como una forma excepcional y soberana de ejercer la autorreflexión de la filosofía y del mundo práctico, dado enfrenta a la filosofía con la experiencia estética. Dicha confrontación de la estética y de la reflexión filosófica formarían aquello que Menke denomina una "dialéctica” de la estética. Tal relación dialéctica se constituiría en un punto negativo, no positivo, pues dialéctica, en este contexto, supone que es (y sigue siendo) un conflicto. En varios de sus ensayos, Menke emplea la vieja disputa entre filosofía y poesía que presentaba Platón como dos formas diferentes de conocimiento. La diferencia entre filosofía y poesía representa modos de reflexión acerca de nuestra práctica ordinaria de la comprensión y la representación. Menke afirma que mientras la filosofía busca la conceptualización y estabilización de los sentidos de la experiencia, la poesía permite de ampliar los sentidos de la experiencia y, al mismo tiempo, reflexionar sobre tales sentidos a los fines de llevar a cabo su crítica. Por lo tanto, Menke (2011) utiliza dicha noción para definir la estética como un modo desestabilizador y, a su vez, productivo de la filosofía que promueve una mejor filosofía. No es casual que vuelva a figuras como la fuerza en Baumgarten, la ironía romántica de Friedrich Schlegel y el juego de fuerzas en Kant, como figuras estéticas que "hacen efecto de tal forma que en uno y el mismo movimiento producen algo y lo vuelven a disolver (...) las fuerzas estéticamente liberadas vuelven siempre a disolver lo que han producido" (Menke, 2011, p. 157).

A partir de esta conceptualización, la EE parece distinguirse por una lógica negativa que aplazaría continuamente las identificaciones reductoras de la experiencia. Dicha negatividad supondría un aplazamiento infinito que eludiría 
cualquier comprensión hermenéutica, pues la experiencia negativa de la estética tendría la capacidad de liberar al objeto de la comprensión. Inspirado en la Teoría estética de Adorno y en la interpretación de Derrida sobre Artaud, Menke sugiere pensar la EE a partir de la posibilidad propia del arte como una forma de diferenciación de la razón, como suplemento, simulacro o juego. Si bien, tanto Derrida como Adorno ofrecerían la posibilidad de combinar, sin reducir, la autonomía con la soberanía, Menke prefiere pensar esas categorías no como oposición, sino en una conexión fructífera entre ambas, con el fin de mostrar su efecto revolucionario y crítico, ya sea a nivel de la razón (Derrida) o de la sociedad (Adorno). Si el proyecto de Adorno consistiera en observar de qué modo el cumplimiento de la promesa del arte "se enreda [...] en una antinomia", entonces, "el arte solo puede afirmar que es más que mera apariencia, ya que es nada más que apariencia"; Derrida, igual que Adorno, "le atribuye al arte [...] un potencial de trascender la razón precisamente en aquella forma que el arte obtuvo únicamente a través de la diferenciación de dicha razón" (Menke, 2011, p. 40). En ambos casos, Menke buscaría destacar una común negatividad que le otorgue al arte un lugar soberano, en la medida en que este pueda ser entendido "como subversión de la razón no-estética" (Menke, 2011, p. 42). Tal negatividad puede identificarse en el nivel de la EE si tenemos en cuenta que liberar al objeto artístico del entendimiento lo pondría en referencia a la lógica del proceso de experiencia.

En virtud de estas conceptualizaciones, Menke (2011) sostiene sobre la EE:

Cualquier acto de experiencia estética empieza con intentos aislados de determinar su objeto; sin embargo, estos obtienen una cualidad específicamente estética únicamente en el devenir que asume y transforma dichas determinaciones. La ejecución de esta transformación es lo que denominamos experiencia estética; y el concepto de negatividad pretende indicar la lógica de esa transformación: la experiencia estética consiste en la negación de todas aquellas determinaciones sin las cuales no podría surgir. Esta tesis del proceso estético es aquel que perturba, irrita, suspende o niega los intentos de identificación o de determinación, es un lugar común de la teoría del arte. [...] La experiencia estética no niega las identificaciones de su objeto oponiendo otras sino reproduciendo el proceso de su formación de manera tal que este ya no se consuma en ningún resultado (p. 45). 
Según Zuidevaart (2007), la negatividad de Menke permite concebir la EE como "un intento de comprensión y una negación de ese intento a la vez. En la experiencia estética el esfuerzo ineludible para entender la obra de arte está, inevitablemente, subvertido" (p. 20)2. En consecuencia, Menke se centraría en la EE como un modo distintivo de otros modos de relacionarse con el mundo. Por ello, la noción de negatividad estética es empleada a efectos de distinguir la EE de la conciencia ordinaria. Dicha negatividad de la experiencia le permitiría ser distinta y diferente de otros modos de experiencia, pero también la limitaría en el momento de interactuar con otros modos de tratar con el mundo. Precisamente en este punto se detienen las críticas de Ruth Sonderegger.

\section{Ruth Sonderegger: crítica de la EE}

Mientras Menke le asigna a la EE la posibilidad de extender la reflexión estética a otros campos que no se circunscriben al arte, Sonderegger tiene la sospecha de que en ese intento hay vestigios de un momento ideológico que conlleva la pérdida de relación con el mundo. El beneficio de la soberanía, adjudicada a la experiencia estética, podría ponerse en cuestión si atendemos al hecho de que su prioridad impide ver la política en el arte y su adecuada tematización. A dicha postura, Sonderegger le concede que hace posible la experiencia de obras de arte, en el sentido de una búsqueda constante de experimentar algo dotado por la disposición de la repetición, la variación y la diferencia. Pero advierte que el objeto artístico también debe ser continuamente experimentado como la colección de ocurrencias del material, el cual no solo interrumpe una conversación en un contexto hermenéutico de representación. Su objeción radicaría en no descuidar el núcleo formal de la experiencia, pues esta no puede reducirse a un aplazamiento indefinido de identificaciones o a la mera perturbación de algún signo. A juicio de Sonderegger, la EE tendría que evitar abandonar los objetos y, al mismo tiempo, reconstruir permanentemente la representación, la forma y el material. La autora reemplaza la oposición entre el signo y la cosa y su relación con el mundo, por representación, forma y material, para dar cuenta de la limitación

$2 \mathrm{Al}$ respecto, véanse las críticas a la supuesta interpretación errónea de Menke sobre Adorno en Zuidevaart, 2007. 
que el concepto de EE podría retener. El complejo campo del arte podría explicarse como una experiencia relacionada con el objeto; sin embargo, su relación es primordialmente individual. No podemos entender, según esta perspectiva, el aplazamiento al infinito que la EE realizaría al impugnar las identificaciones, que Menke guarda de Derrida, ingenuamente, como si la experiencia no tuviera ninguna reacción para el mundo. Esa experiencia no se juega exclusivamente en la cabeza del receptor. La EE, en todo caso, definiría la relación con un objeto material, con una cosa, es decir, con una representación del mundo. Por tanto, la intención sería volver notoria la dimensión del trabajo de la obra, la restitución y la oposición de la cosa y el signo que se extiende en todo el aspecto de la forma, es decir, no puede reducirse a ninguno de los dos elementos en la oposición.

Ruth Sonderegger asume esta crítica del concepto de EE à la Bubner y, además, reclama la necesidad de incluir en este concepto una relación con el mundo. La crítica se dirige a una teoría del arte que se acerca a su objeto bajo los lineamientos del concepto de EE. De acuerdo con las críticas de Bubner sobre la EE de su ensayo "Sobre algunas condiciones de la estética actual" (2010), a principios de los años setenta existían dos razones para mirar de nuevo a la teoría de la EE de Kant. La primera, la desaparición empírica de las llamadas obras de arte tradicionales y cerradas en favor de acontecimientos estéticos que no podían entenderse a partir de esas antiguas concepciones sobre la obra de arte. La segunda sostiene que tal desaparición no es empírica, sino que es válida para cualquier normativa crítica de la verdad de la obra de arte se trata, en especial, de la verdad del arte que los filósofos han enaltecido. Las críticas de Bubner, cabe apuntar, estarían dirigidas principalmente en contra de, por un lado, la estética del marxismo y, por otro lado, la estética de la verdad de la hermenéutica de Gadamer. Ambas perspectivas, según Bubner, intentarían resolver los problemas filosóficos en la dimensión artística, limitando la verdad del arte a la verdad filosófica. Con la ayuda de los conceptos de obra y verdad como categorías intempestivas, los teóricos de la verdad harían mejor la filosofía del arte. Las estéticas heterónomas, como las califica Bubner, verían una forma de tutelaje del arte mediante el lenguaje filosófico. Si aceptamos esas perspectivas, el arte estaría en la obligación de revelar verdades más profundas, incluso debería develar verdades filosóficas más allá de lo que la filosofía misma se atrevería. Pero lo que inicialmente parece una revalorización del arte es para Bubner su devaluación; esto quiere decir, reducir 
el arte a la filosofía. De ese modo, el arte perdería su propia lógica, dado que el peligro con estas estéticas heterónomas sería la subordinación del arte a la filosofía. Esa afinidad entre arte y filosofía permitiría el esclarecimiento mutuo en tanto el horizonte del problema sea compartido. Sin embargo, Bubner desconfía de que en ese esclarecimiento recíproco se esté cifrando el dominio de la filosofía sobre el arte. Dados estos problemas, Bubner (2010) propone abandonar el concepto de obra de arte, pues "no queda otro camino metódico que tomar como punto de partida la experiencia estética” (p. 392). Bubner (2010) cree encontrar que el único medio de interpretar el concepto de EE estaría disponible en el concepto de juicio reflexionante de la estética kantiana. La posibilidad de indeterminación conceptual y búsqueda permanente de la facultad reflexionante ofrecería no solo una función mediadora, también implica que

[e]l sujeto se experimenta a sí mismo en sus operaciones, lo que solo puede suceder si no se da ninguna determinación obligatoria. El objeto que desencadena este proceso permanece indeterminado; por esta razón, la relación con él tiene lugar en el modo de la sensibilidad, sin que sea dictada por el interés sensible en tener o disfrutar el objeto. El sentimiento de sí mismo tampoco desarrolla un concepto definido de sujeto, pues dicho sentimiento se cumple solo en la operación pura con motivo de la experiencia de una afectación sensible (p. 397).

Por ello, Bubner (2010) encuentra la EE en la encrucijada y la tensión entre "ser afectado sensiblemente y una producción creativa" (p. 397). Dicha tensión mostraría que el arte opera libremente, pues no permanece ni ligado al objeto, ni al sujeto, y el único concepto adecuado para definir esta autonomía es el concepto de apariencia. En su análisis, el juicio reflexionante debería concebirse, al igual que el concepto de apariencia, como aquello "no autónomo que se ha vuelto autónomo" (Bubner, 2010, p. 399). El tradicional esquema de la teoría del conocimiento sería insuficiente para comprender la apariencia o, dicho kantianamente - como le gusta a Bubner-, la operación. Recurrir a la apariencia como forma de caracterizar el juicio reflexionante y, por tanto, a la $E E$, le permite al autor encontrar una lógica especial del arte que la salve de las pretensiones universalistas de la verdad filosófica. Si el punto de partida, según Bubner, es la EE y su estructura, el juicio reflexionante, la apariencia estética, 
sería la posibilidad ontológica de la existencia del arte como separado de la filosofía (autónomo):

Arte es apariencia en su autonomía y, por lo tanto, el arte es incapaz de calificarla como apariencia. La apariencia que no puede ser reconocida como apariencia se considera engaño y tiene que abandonarse en cuanto se presente la comprensión. El arte, que tiene su ser en la autonomía de la apariencia, no puede, por lo tanto, ser legitimado jamás mediante el concepto lógico de la apariencia referida a la verdad (Bubner, 2010, p. 400).

Bubner no está de acuerdo con poner al arte y su apariencia autónoma en relación con la verdad exigida por la filosofía. Reconoce que Platón, en su intento de desterrar el arte del Estado ideal, beneficia y considera seriamente la posibilidad de una autonomización de lo no autónomo. El peligro que Platón advertía le parece a Bubner sintomático, pues explica los efectos que la apariencia artística posee sobre la verdad. Existiría en la consideración de Bubner, según nuestro análisis, un régimen autárquico de la apariencia estética respecto de la verdad; su paradoja no implica ponerla en relación con algo que encubre o que es anterior a ella, sino con una lógica propia. Para Bubner, la intención de Menke, Seel y Wellmer, los "teóricos de la experiencia estética", de considerar a la EE en relación con las potencialidades del arte para encontrar una verdad implicaría renunciar a la autonomía del arte, subsumiéndola en los planes de la verdad filosófica o autocrítica de la misma. La autonomía que la apariencia estética ofrecería no sería aprovechada, a juicio de Bubner (2010), por la estética filosófica, que se esfuerza en "reflejar solo el concepto en el arte en lugar de concebir conceptualmente el arte" (p. 401). La oposición a los teóricos mencionados, entonces, se centraría en la insistencia de estos en asignar al arte un valor de verdad como derecho. No solo que vuelven a un tipo de consideración de la EE propia de las estéticas heterónomas, sino que además adjudicaría a la EE un acceso privilegiado al mundo, más verdadero incluso que otras formas de conocimiento. No parece ser legítima para Bubner la aplicación de las categorías estéticas en una teoría del conocimiento en la cual la apariencia se vería claramente afectada en su desvalorización. El autor defiende la idea de que el arte no tenga nada para decirle a la filosofía, ya que en dicha posibilidad radica el beneficio de una estética filosófica. La apariencia estética sería la única estructura capaz de sostener a la EE que se resiste a 
la aprehensión conceptual. Nuevamente, Bubner (2010) recurre a un modelo de autarquía estética por medio de la apariencia, pero ahora incluye la exposición de la $\mathrm{EE}$ en la apariencia artística. $\mathrm{Al}$ respecto, señala:

Es más bien la inaprehensible autonomía, no sostenida por nada, de los fenómenos estéticos la que invita al pensamiento a dominarlos, dejándolos, sin embargo, completamente desamparados. En el arte aparece algo que puede y quiere ser comprendido, pero que definitivamente no resiste ninguna intervención (p. 402).

Si bien Sonderegger sigue a Bubner, no acepta que la autonomía del arte se establezca solo al precio del desplazamiento de la verdad o que, como indica Bubner (2010), haya arte "solo en el ámbito de la actividad de la reflexión desencadenada por ciertos objetos sensibles, la cual produce operaciones puras en un movimiento que nunca termina" (p. 399). Sonderegger considera que, aunque el arte incorporará esta exigencia, tanto como la rechazará, su propia lógica nunca ha dado mucha seguridad. Bubner, en todo caso, lograría arrebatar el arte a las trampas de la filosofía, pero su camino sería equivocado. Incluso cuando las estéticas heterónomas puedan definir el arte en términos de su capacidad para transmitir la verdad, negando con ello la diferencia entre el arte y la divulgación del mundo, de un lado, la filosofía, la crítica social o la teología negativa, de otro, Bubner no podría llegar a la conclusión de que a partir de este hecho la categoría de la verdad sea desechada. El error de Bubner estaría en su consideración del arte como espacio desprovisto o suspendido de verdad, como también su apreciación acerca de que la discusión deba ser remitida de nuevo a la cuestión de los contenidos en el arte. Bubner, entonces, asumiría equivocadamente que el arte solo es realmente autónomo cuando se descarta el contenido y las exigencias de verdad. La conclusión de Bubner respecto a que la salvación de la autonomía del arte estaría dada en el reconocimiento de la EE como un juego de ella misma, supone confundirla con la autonomía de la experiencia subjetiva y de su reconocimiento especial del yo en relación con el mundo. Para Sonderegger (2010), sin embargo, se puede pensar en contra de Bubner que

[...] uno puede, por supuesto, considerar plausibles las teorías de la experiencia estética que tengan en consideración la importancia de la objetualidad. Sin embargo, ellas son limitadas, de hecho, el objeto del arte no se reduce 
automáticamente a ser un (mayor) portador de la verdad. Tal intento es para hablar de la experiencia estética como un espacio entre cosa y signo. A raíz de esto, voy a explicar, brevemente, por qué el dúo cosa y signo deben interpretarse como la tríada de material, forma y representación en el modo de impartir información. Entonces, me gustaría seguir la intuición de que incluso esta tríada todavía tiene algo de malo en ello, pues se explica el complejo campo del arte como una experiencia que, de hecho, puede estar relacionada con el objeto, pero ella es fundamentalmente individual. La infinitud estética, que también juega un papel importante en los dos teóricos más importantes de la obra de arte entre cosa y signo -Valéry y Derrida- es, creo, incomprendida si nosotros, como Bubner, la vemos como la idea de que la experiencia estética no tiene ninguna reacción para el mundo, sino que se juega esencialmente en la cabeza del receptor, en todo caso, donde la facultad de reconocimiento se encuentra (pp. 5-6).

Sonderegger defiende que la verdad de la EE no necesariamente debería interpretarse como un modelo epistemológico. Experimentar algo como una obra de arte significaría experimentarlo como la representación de una pieza del mundo, de modo que esta representación, como objeto hermenéutico, sea constantemente frustrada por la objetualidad de los elementos de la representación. Contrariamente a Bubner, quien en nombre de una lógica propia del arte refuta la relación con el mundo y la verdad, Sonderegger resguardaría la posibilidad de los objetos, que en la autonomía estética serían compatibles con una comprensión del trabajo entre la verdad y el mundo. En esa dirección, entenderíamos correctamente las obras de arte solo si incluimos la posibilidad de la relación con el mundo como parte de la recepción. Tal relación con el mundo estaría indicada, cree Sonderegger, en al menos dos formas. Por un lado, en el contenido representado en la obra -o sus cuestiones-, que debe ser actualmente significativo para el destinatario específico y, por el otro, en el hecho de que la obra de arte aborda un 'nosotros' como grupo que la recibe. El arte, de ese modo, se referiría de manera oportuna a las cuestiones políticas, esto es, al sentido de lo que es público y compartido.

Precisamente, esta oportunidad sería lo que faltaría en las teorías de la EE, que rechazan la propia política de la observación del arte. La EE, en ese caso, solo sería una dimensión de lo que la obra de arte nos transmite. Tal concepción prohíbe, 
aparentemente, la relación del arte con el mundo. Por eso, el concepto de EE que Sonderegger deduce de la lectura de los "teóricos de la experiencia estética" parece mostrar a la obra de arte como independiente de su contenido y de las relaciones con el mundo. Por lo tanto, su rol debe ser incorporado correctamente en la estética. Es decir, debería ser a la vez extendida y descentrada. Ella ya no es el centro organizador de la aproximación al arte, sino un momento entre otros en este enfoque: del colectivo, de la ficción de los destinatarios, de los objetos, de las instituciones y del mundo no-estético. La EE es comprendida, en ese contexto, como máscara indispensable para la confrontación con el arte. La indicación de Sonderegger (2010) parece estar puesta en evitar que tal experiencia se vuelva controlable para el sujeto individual. A la concepción kantiana y poskantiana la autora opone aquellas prácticas colectivas como el teatro o el documental ${ }^{3}$, donde la EE debería volverse política, pues de lo contrario, quedaría atrapada en la ideología de la apariencia falsa y parcial de su recepción. Por lo tanto, concluye que estos procesos exceden a la EE: "incluso [las EE.EE] obligan a sus sujetos a ir fuera de la zona, no solo de la experiencia estética, sino también del arte. En otras palabras, parte de tomar en serio la experiencia estética es abandonarla" (p. 17).

La preocupación de la autora, entonces, se orienta hacia el modo en el que el compromiso estético tiene que separarse tanto de su propia experiencia, como de la experiencia en su estructura de infinitud. Ambas separaciones suponen también alejarse de aquellos compromisos con las evaluaciones políticas de quienes toman parte en el discurso -en el sentido de justificar un juicio en las críticas, las discusiones privadas o los discursos públicos-. Su advertencia, siguiendo al Paul de Man de los ensayos de La ideología estética, pretende mostrar en definitiva que la estética se puede convertir en ideología en la medida en que siga confundiendo, en este

3 La referencia en el ensayo de la autora es La tercera memoria de Pierre Huyge (1999). Este documental confronta tres versiones de un hecho real. Esas tres narrativas son Dog Day Afternoon [Tarde de perros] de Sidney Lumet, basada en el robo de un banco perpetrado por John Wojtowicz; la cobertura mediática del suceso; y una reconstrucción de los hechos interpretada y narrada por el propio Wojtowicz, que demuestra la influencia de las otras "versiones" sobre sus recuerdos. La tercera memoria se presenta bajo la forma de una exposición de elementos documentales y ficticios que permite medir las diferentes distancias que se entrecruzan entre la realidad tal como la vive el autor y el espectáculo cinematográfico. Huyge lograría llevar a cabo una reinterpretación de una situación según la reapropiación de las representaciones, en este caso, las del cine y las de los medios de comunicación. 
caso, la experiencia con el fenómeno. Si Paul de Man a inicios de los años ochenta identificaba que la estética se habría vuelto ideológica, dado que confundía la referencia lingüística con el fenomenalismo, Sonderegger nota este mismo gesto en el movimiento de la EE defendida por algunos teóricos (Menke, Seel, Wellmer), hasta el punto de haber despolitizado el arte en la ilusión de la apariencia estética.

\section{Consideraciones finales: arte y política}

LAS CRÍTICAS REALIZADAS POR SONDEREgGer parecen plantear al menos dos problemas. El primero, relacionado con la falta de relación de la EE con el mundo, dado que, según vimos, su renuncia a la verdad también implicaría el abandono del objeto. El segundo, relacionado con la despolitización que supondría la EE, dado que prioriza un efecto individual y subjetivo que no puede transmitirse, deviniendo en un momento ideológico. Siguiendo a Jens Szczepanski (2010), quien comenta el artículo de Sonderegger en el mismo dossier donde aparece publicado, podríamos advertir sobre estos puntos algunas objeciones, a efectos de defender la posición de la EE. En primer lugar, se podría pensar en la posibilidad de la relación con el mundo en la teoría de la experiencia. Respecto a ello, Szczepanski no ve en absoluto por qué esto debe excluirse, como supone Sonderegger. La explicación de la EE como la interacción de la relación subjetiva con los objetos del arte que se representa entre cosa y signo parece ser indiferente a la cuestión de la relación con el mundo o la dimensión política de esta experiencia. Una recepción exitosa también debería permanecer dentro del horizonte de esta relación con el mundo. Ya Menke en La soberanía del arte insistía en que, a pesar de la negatividad constitutiva de la EE, que aplazaba cualquier identificación de la razón o de la sociedad, esta no renunciaba a buscar sentido en relación con el mundo (Menke 1997, p. 246)4. No parece claro por qué el concepto de EE necesariamente debería implicar el despido o la inclusión del mundo, como lo describe Sonderegger. La experiencia estética, entonces, sería malinterpretada de una manera cuasi-estetizada si la entendiéramos como la experiencia atemporal de estructuras fijas en la obra, algo que ya había advertido Walter Benjamin.

4 Véase Menke, 1997, p. 246, donde también explica este proceso en relación con las críticas de Derrida a la razón y de Adorno a las pretensiones totalitarias del sentido de la razón. 
Como sostienen Esteban Juárez y Verónica Galfione (2015), los teóricos de la experiencia estética como Menke, Seel y Rebentisch permitirían sostener la necesaria búsqueda de una redefinición del concepto de obra de arte, pero también permiten pensar que la diferenciación de la "experiencia estética de aquellas relaciones cosificadoras que tendrían lugar en las demás esferas de la realidad social” no implica "renunciar por ello a la posibilidad de dar cuenta de los hechos artísticos contemporáneos" (Juarez y Galfione, 2015, p. 427).

La conceptualización de Sonderegger parece mostrar que existe cierta incompatibilidad entre la EE y contenidos políticamente relevantes, dejando a la primera como un mero juego interno para la obra, con materiales dados y con su disposición formal. Al contrario, es precisamente ese juego lo que la vuelve política; la subversión de la EE se encuentra en tomar elementos extraestéticos, precisamente, porque tiene una relación intrínseca con la verdad. La EE, en la descripción de Sonderegger, no sería distinguida en los dos momentos que en Menke se podrían observar. Según este autor, la EE, antes de asumir el gusto individual, debería tener en cuenta una dimensión comunitaria. Previamente al gusto, se produce un proceso de formación colectiva de carácter social que excede cualquier subjetivación individual, pues, para Menke, lo que se pone en juego es la fuerz $a^{5}$. La EE, de hecho, crea relaciones con el mundo con el fin de permitir la posibilidad de un encuentro conveniente y significativo entre sujeto y objeto. Por lo tanto, parecería apropiado integrar la dimensión políticamente relevante de las obras de arte en una teoría de la experiencia, en lugar de despedir a esta última como aquello que no tiene relación con el mundo. En cualquier caso, las críticas de Sonderegger se extralimitan. Parece ir más allá del concepto en cuestión con la dudosa ecuación entre relación con el mundo y los contenidos políticos ${ }^{6}$. El sujeto que experimenta no es más que parte de una red hecha

5 En "Force: Towards an Aesthetic Concept of Life", Menke (2010) desarrolla las distintas formas de acceder al concepto de fuerza con el cual interpreta toda la tradición estética. En este caso, el pensador alemán lo ubica en relación con el concepto de vida estética, en oposición a vida biológica.

6 Sonderegger (2014), en "Do We Need Others to Emancipate Ourselves? Remarks on Jacques Rancière”, vuelve a situar los componentes políticos de la estética a partir de la propuesta de Jacques Rancière. En esta ocasión, sus planteos parecen encontrarse más cercanos a los teóricos de la experiencia estética que a sus críticas à la Bubner. 
de un colectivo: los objetos, las instituciones y el mundo. En contra de la tesis de que esto significaría trascender o relativizar la EE, podría refutarse que todo esto también se puede entender como momentos de la propia EE. La relación con el mundo no es ajena a la EE, sino constitutiva de ella. Sin la relación con el mundo, es decir, sin la creación de una relación entre la obra de arte y sus destinatarios, la cual tiene en cuenta el contexto específico, no habría EE en absoluto (Szczepanski, 2010).

La política -o mejor aún, la relación con el mundo- no pareciera ser ajena a la EE, sino constitutivamente incorporada en ella, porque los sujetos solo tienen experiencias estéticas si los objetos y sus elementos tienen relevancia para los sujetos ${ }^{7}$. El significado de la eficacia subversiva de las obras de arte es un tema central que no se puede descuidar, pero eso no supone reducirlo a las discusiones en torno a la verdad epistemológica de las mismas. Sin embargo, la pregunta sería si la relevancia del juego de la experiencia se debe explicar, terminológicamente, atribuyendo contenidos políticos a las obras de arte. En definitiva, la relación de la obra con el mundo es, por lo tanto, irreductiblemente multidimensional desde el principio. $\mathrm{Al}$ reducir el arte a la crítica política, no hay razón para ver por qué la tradición artística debería ser la mejor manera de quejarse del mundo explícitamente experimentable.

$\mathrm{Si}$, como sostiene Juliane Rebenstisch, las obras de arte posteriores a 1960 cuestionaron la unidad de las formas artísticas, la división de los géneros, así como la filosofía de la historia del arte que les subyacía, habría que aceptar, entonces, algún modo de objetivar políticamente la obra. En ese sentido, parece adecuado que la filosofía comience a pensar en la EE como una categoría fundamental. Este giro supone "una crítica de la idea modernista de determinación objetiva de la obra dejando así la cuestión de la determinación de la obra a interpretaciones potencialmente discrepantes entre sí" (Rebentisch, 2011, p. 61). Una obra de arte que fija de forma inequívoca su contenido político ya no sería

7 Juliane Rebentisch apela a un argumento similar para indicar cómo la experiencia estética debería ser entendida en el marco de una historicidad cambiante, evitando así la interpretación ideal del arte o una interpretación subjetivista y privada de la experiencia estética. Véase Rebentisch (2011, pp. 84-85). También pueden consultarse en este sentido los distintos artículos que problematizan los límites de la crítica, el juicio y la subjetividad con relación al arte contemporáneo en Rebentisch (2012). 
arte, sino solo una declaración política. No es casual que muchos de los teóricos de la EE en los últimos años hayan comenzado a prestar atención a aquellas teorizaciones provenientes de la filosofía política y la sociología. Para muchos de estos teóricos, el pensamiento de Jacques Rancière tal vez sea el modelo de articular las exigencias de pensar el arte en un nuevo horizonte posfundacional ${ }^{8}$. La advertencia del pensador francés acerca de cómo la estética se constituiría en un régimen de lo visible se combina en este contexto con las observaciones y diagnósticos de Luc Boltanski y Eve Chiapello en El nuevo espiritu del capitalismo (2002) y con una relectura en el ámbito alemán de la obra de Pierre Bourdieu. A partir de estas teorizaciones, la reflexión filosófica de la estética habría comenzado a encontrar algunas respuestas sobre la nueva forma de juzgar al arte contemporáneo y de pensar en su estatuto\%. En dos simposios organizados por la cátedra Jorge Oteiza de la Universidad de Navarra entre los años 2010 y 2012, distintos teóricos dedicados a la investigación de la estética filosófica-Menke, Andrea Giunta, Terry Smith, Christiane Voss, Bojana Kunst, Alexander García Dütmann y Dieter Roelstraete- ${ }^{10}$ se reunieron en torno a la elucidación de dos preguntas necesarias y casi repetitivas: ¿qué es el arte contemporáneo? y ¿se puede juzgar el arte contemporáneo? Ambos interrogantes parecen mostrar las dificultades con las cuales la estética filosófica se enfrenta al arte actual. Aunque nuestra atención en este trabajo no estuvo puesta en resolver esas dificultades, sí parece necesario

8 Tanto en "Estetización: ¿qué relación existe entre la estetización y la democracia, por qué se la debería defender, por qué motivo es necesaria la filosofía para hacerlo y qué se sigue de este hecho para la crítica de la sociedad?", como en "Realismo hoy: arte, política y crítica de la representación”, Rebentisch (2013a, 2013b) desarrolla estas perspectivas en beneficio de una mirada estética sobre la política, intentando salvar a la misma del reduccionismo de la estetización posmoderna de los años noventa.

9 Son orientativas para esta discusión las observaciones de Andrea Giunta (2014) sobre el concepto de lo contemporáneo en el arte. Si bien su pregunta busca indagar las rupturas conceptuales, sintomáticas y formales del arte contemporáneo en América Latina, revela algunos supuestos claves del panorama actual. También pueden consultarse las discusiones en formato de entrevistas de Anna María Guasch (2012), quien sostiene un diálogo con distintos sectores intelectuales preocupados por los cambios y transformaciones en el arte moderno y contemporáneo.

10 Véase Rebentisch, 2012. Varios de estos análisis también pueden consultarse directamente en los proyectos de investigación de estos teóricos en www.sfb626.de. 
indicar, para finalizar, que la categoría de experiencia estética surgida al calor de estas discusiones podría constituirse como un modo de descifrar el enigma del arte de nuestro tiempo. Al menos esto parece mostrar la discusión actual que tiene por delante repensar el modelo de subjetividad de las prácticas artísticas y su dimensión política sin caer en viejas y obsoletas fórmulas como la oposición entre arte y filosofía o arte y política.

\section{Referencias}

Boltanski, L. \& Chiapello, È. (2002). El nuevo espiritu del capitalismo. Madrid: Akal.

Bubner, R. (2010). "Sobre algunas condiciones de la estética actual". En: Acción, historia y orden institucional. Ensayos de filosofía práctica y una reflexión sobre estética (pp. 357-410). Buenos Aires: Fondo de Cultura Económica.

Fricke, C. (2001) Zeichenpronze und ästhetiche Erfahrung. Múnich: Fink.

Giunta, A. (2014). ¿Cuándo empieza el arte contemporáneo? Buenos Aires: Fundación arteBA.

Guasch, A. M. (2012). La critica discrepante. Entrevistas sobre arte y pensamiento actual (2000-2011). Madrid: Ediciones Cátedra.

Jay, M. (1997). “Mimesis and Mimetology: Adorno and Lacoue-Labarthe”. En: Huhn, T., \& Zuidervaart, L. (Eds.). The Semblance of Subjectivity. Essays in Adorno's Aesthetic Theory (pp. 29-54). Cambridge: MIT Press.

Jay, M. (2001). "La crisis de la experiencia en la era postsubjetiva". En: Prismas. Buenos Aires: UNQ.

Jay, M. (2009). Cantos de experiencia. Buenos Aires: Paidós.

Juárez, E. \& Galfione, M. V. (2015). "Experiencia estética después de Adorno. Reflexiones en torno a Wellmer, Bertram y Rebentisch". Kriterion, (132), 413-431.

Kern, A. (2000) Schöne Lust. Eine Theorie der ästhetischen Erfahrung nach Kant. Francfort del Meno: Suhrkamp.

Menke, C. (1997). La soberanía del arte. Madrid: Visor.

Menke, C. (2010). "Force: Towards an Aesthetic Concept of Life". MLN, 125(3) [edición alemana], 552-570. 
Menke, C. (2011). Estética y negatividad. México: Fondo de Cultura Económica.

Ratté, M. (1997). "Christoph Menke: herméneutique, déconstruction et raison dans le problème de l'expérience esthétique”. Horizons philosophiques, 7(2), 107-126.

Rebentisch, J. (2011). “Autonomía y progreso en el arte”. En: Alberrio, A. (Ed.). ¿Qué es arte contemporáneo hoy? (pp. 57-88). Simposio internacional con ocasión de la Cátedra Jorge Oteiza de la Universidad Pública de Navarra, Pamplona, España.

Rebentisch, J. (Ed.). (2012). Juzgar el arte contemporáneo. Simposio internacional con ocasión de la Cátedra Jorge Oteiza de la Universidad Pública de Navarra, Pamplona, España.

Rebentisch, J. (2013a). "Estetización: ¿qué relación existe entre la estetización y la democracia, por qué se la debería defender, por qué motivo es necesaria la filosofía para hacerlo y qué se sigue de este hecho para la crítica de la sociedad?”. En: Galfione, M. V. \& Juárez, E. (Eds.). Modernidad estética y filosofía del arte I. La estética alemana (pp. 111-138). Córdoba: UNC.

Rebentisch, J. (2013b). "Realismo hoy: arte, política y crítica de la representación”. En: Galfione, M. V. \& Juárez, E. (Eds.). Modernidad estética y filosofía del arte I. La estética alemana (pp. 139-167). Córdoba: UNC.

Schaeffer, J. M. (2013) “Experiencia estética: placer y conocimiento". Boletín de estética. Año VIII, Primavera 2013, № 25. Pp. 5-34.

Seel, M. (2010). Estética del aparecer. Buenos Aires: Katz.

Sonderegger, R. (2010). "The Ideology of the Aesthetic Experience. An Attempt at Repoliticizing”. disponible en: Sonderforschungsbereich 626, ed., Between Thing and Sign, Berlin 2010, http://www.sfb626.de/en/veroeffentlichungen/sonderegger.pdf.

Sonderegger, R. (2000) Für eine Ästhetik des Spiels. Hermeneutik, Dekonstruktion und der Eigensinn der Kunst. Fráncfort del Meno: Suhrkamp.

Sonderegger, R. (2014) "Do We Need Others to Emancipate Ourselves? Remarks on Jacques Rancière". Krisis. Journal of Contemporary Philosophy, (1), 53-67.

Shusterman, R. \& Tomlin, A. (2008). Aesthetic Experience. New York: Routledge. 
Szczepanski, J. (2010). "Commentary on Ruth Sonderegger's The Ideology of the Aesthetic Experience: An Attempt at Repoliticizing". En: Between Thing and Sign [Sonderforschungsbereich 626]. Berlín: Freie Universität Berlin. Recuperado de http://www.sfb626.de/en/veroeffentlichungen/szczepanski.pdf

Wellmer, A. (1991) "Verdad, apariencia, reconciliación. La salvación estética de la Modernidad según Adorno", Sobre la dialéctica de modernidad y postmodernidad La crítica de la razón después de Adorno. Madrid, Visor.

Zuidervaart, L. (1991). Adorno's Aesthetic Theory: The Redemption of Illusion, Cambridge: MIT Press.

Zuidevaart, L. (2007). “Transgression or Transformation”. En: Social Philosophy after Adorno (pp. 16-47). Cambridge: Cambridge University Press. 